\title{
An intrinsic circadian clock of the pancreas is required for normal insulin release and glucose homeostasis in mice
}

\author{
L. A. Sadacca • K. A. Lamia • A. S. deLemos • B. Blum • \\ C. J. Weitz
}

Received: 9 June 2010 / Accepted: 9 August 2010 /Published online: 3 October 2010

(C) The Author(s) 2010. This article is published with open access at Springerlink.com

\begin{abstract}
Aims/hypothesis Loss of circadian clocks from all tissues causes defective glucose homeostasis as well as loss of feeding and activity rhythms. Little is known about peripheral tissue clocks, so we tested the hypothesis that an intrinsic circadian clock of the pancreas is important for glucose homeostasis.

Methods We monitored real-time bioluminescence of pancreas explants from circadian reporter mice and examined clock gene expression in beta cells by immunohistochemistry and in situ hybridisation. We generated mice selectively lacking the essential clock gene Bmall (also known as Arntl) in the pancreas and tested mutant mice and littermate
\end{abstract}

L. A. Sadacca and K. A. Lamia contributed equally to this work.

Electronic supplementary material The online version of this article (doi:10.1007/s00125-010-1920-8) contains supplementary material, which is available to authorised users.

L. A. Sadacca K. A. Lamia · A. S. deLemos · C. J. Weitz $(\varangle)$

Department of Neurobiology, Harvard Medical School,

220 Longwood Ave,

Boston, MA 02115, USA

e-mail: cweitz@hms.harvard.edu

A. S. deLemos

Gastrointestinal Unit, Department of Medicine,

Massachusetts General Hospital,

Boston, MA, USA

B. Blum

Harvard Stem Cell Institute, Department of Stem Cell

and Regeneration Biology, Harvard University,

Cambridge, MA, USA

Present Address:

K. A. Lamia

The Salk Institute for Biological Studies,

La Jolla, CA, USA controls for glucose and insulin tolerance, insulin production and behaviour. We examined islets isolated from mutants and littermate controls for glucose-stimulated insulin secretion and total insulin content.

Results Pancreas explants exhibited robust circadian rhythms. Clock genes Bmall and Perl were expressed in beta cells. Despite normal activity and feeding behaviour, mutant mice lacking clock function in the pancreas had severe glucose intolerance and defective insulin production; their isolated pancreatic islets had defective glucosestimulated insulin secretion, but normal total insulin content. Conclusions/interpretation The mouse pancreas has an autonomous clock function and beta cells are very likely to be one of the pancreatic cell types possessing an intrinsic clock. The Bmall circadian clock gene is required in the pancreas, probably in beta cells, for normal insulin secretion and glucose homeostasis. Our results provide evidence for a previously unrecognised molecular regulator of pancreatic glucose-sensing and/or insulin secretion.

Keywords Circadian clock - Glucose homeostasis . Insulin $\cdot$ Islets

$\begin{array}{ll}\text { Abbreviations } \\ \text { BMAL1 } & \text { Brain, muscle Arnt-like 1 } \\ \text { KRBH } & \text { KRB containing bicarbonate and HEPES } \\ \text { SCN } & \text { Suprachiasmatic nucleus } \\ \text { ZT } & \text { Zeitgeber }\end{array}$

\section{Introduction}

Circadian clocks are cell-autonomous molecular oscillators that drive daily rhythms of physiology and behaviour. In mammals, the clock of the suprachiasmatic nucleus (SCN) 
in the brain drives the rest-activity cycle and modulates physiology through autonomic and neuroendocrine control of visceral organ function [1]. Many peripheral tissues have intrinsic clocks, but at present there is only limited information about their functions [2].

Mice with germ-line mutations of circadian clock function have abnormal glucose homeostasis, regardless of whether the mutation affects positive (Clock [3] or Bmall [also known as Arntl] $\left.]^{-/}[2,4]\right)$ or negative $\left(\right.$ Perl $^{-/}$, $P e r 2^{-/-}$[2]) elements of the clock feedback loop. This suggests that glucose homeostasis abnormalities arise from disrupted clock function rather than from an unrelated function of a particular clock gene. Because these mice lack clock function in all tissues, abnormal glucose homeostasis could have arisen from (1) a defect of the SCN clock (and the consequent abnormal activity and feeding), (2) other brain clocks or (3) clocks of peripheral tissues. Bmall ${ }^{-/}$ mice have significantly reduced circulating insulin [2], so it is plausible that a clock within the pancreas, particularly in the insulin-producing beta cells of the islets of Langerhans, might be crucial for glucose homeostasis.

\section{Methods}

Mice Mice (Pdxl-Cre) were provided by D. Melton (Harvard University, Department of Molecular and Cellular Biology, Cambridge, MA, USA) [5]. We generated Bmall ${ }^{\text {lox/lox }}$ [6] and Bmall-Luc mice [7]. Mice (hybrid C57BL/6;129 background) were entrained to a $12 \mathrm{~h}$ light-dark cycle for 2 weeks prior to experiments. Genotyping was performed as described [6]. Studies were performed in accordance with a protocol approved by the Harvard Medical School Standing Committee on Animals.

Real-time recordings of circadian bioluminescence Explants of pancreas from Bmall-Luc circadian reporter mice were dissected, placed in medium (2 $\mathrm{ml}$ DMEM, supplemented with protease inhibitors, $10 \%$ [vol./vol.] FBS, $100 \mathrm{U} / \mathrm{ml}$ penicillin, $100 \mu \mathrm{g} / \mathrm{ml}$ streptomycin and $250 \mu \mathrm{mol} / \mathrm{l} \mathrm{D}-$ luciferin), cultured and monitored for bioluminescence as described [7].

Glucose and insulin tolerance tests Glucose and insulin tolerance tests, and insulin determination were performed as described [2]. For glucose tolerance tests across the circadian cycle, manipulations were performed under dim red light.

Immunohistochemistry and in situ hybridisation Mice with Bmall deleted from the pancreas (Panc-Bmall ${ }^{-/}$) and Pdx1-Cre littermates ( $n=3$ for each) were killed and the pancreas dissected into $4 \%$ formaldehyde in PBS. Pan- creases were post-fixed $\left(2 \mathrm{~h}, 4^{\circ} \mathrm{C}\right)$, fixative was removed by washes in PBS and tissue was cryoprotected overnight $\left(4^{\circ} \mathrm{C}, 30 \%\right.$ [wt $/ \mathrm{vol}$.] sucrose in PBS $)$. Pancreases were then embedded and frozen, and $10 \mu \mathrm{m}$ sections were cut on a cryostat, dried and stored at $-80^{\circ} \mathrm{C}$.

Insulin immunohistochemistry was performed using guinea pig anti-insulin (1:700; Dako, Glostrup, Denmark), followed by donkey anti-guinea pig secondary antibody (1:200; Invitrogen, Carlsbad, CA, USA). For double-label immunostaining with in situ hybridisation, fluorescence in situ hybridisation was performed as described in the Electronic supplementary material (ESM) Methods. Estimation of islet number was performed by counting the number of islets (identified by insulin immunostaining) per $10 \mu \mathrm{m}$ section of four to seven sections per mouse, using three mice per genotype. Islet area and staining intensity (1214 islets per genotype) were measured by circling islets in insulin immunofluorescence images and measuring area and mean grey value with ImageJ software (ESM Methods).

Glucose-stimulated insulin secretion Pancreatic islets were isolated from mice and incubated overnight for recovery in DMED containing $1 \mathrm{mg} / \mathrm{ml}$ glucose (Sigma, St Louis, MO, USA) and 10\% FBS. For glucose-stimulated insulin secretion, isolated islets were incubated in KRB containing bicarbonate and HEPES (KRBH; $129 \mathrm{mmol} / \mathrm{l} \mathrm{NaCl}$, $4.8 \mathrm{mmol} / 1 \mathrm{KCl}, 2.5 \mathrm{mmol} / 1 \mathrm{CaCl}_{2}, 1.2 \mathrm{mmol} / 1 \mathrm{KH}_{2} \mathrm{PO}_{4}$, $1.2 \mathrm{mmol} / 1 \mathrm{MgSO}_{4}, 5 \mathrm{mmol} / 1 \mathrm{NaHCO}_{3}, 10 \mathrm{mmol} / \mathrm{l} \mathrm{HEPES}$, $0.1 \%$ (vol./vol.) BSA) with $2.8 \mathrm{mmol} / 1 \mathrm{D}$-glucose for a $1 \mathrm{~h}$ for wash. Triplicates of ten islets were then incubated for $75 \mathrm{~min}$ in KRBH buffer containing either low $(2.8 \mathrm{mmol} / \mathrm{l})$ or high $(16.7 \mathrm{mmol} / \mathrm{l}) \mathrm{D}$-glucose. Insulin in supernatant fractions was measured using an ELISA kit (Mouse Insulin Ultrasensitive; Alpco Diagnostics, Salem, NH, USA). For insulin content, groups of ten isolated islets were incubated overnight at $-80^{\circ} \mathrm{C}$ in acidic ethanol $(1.5 \%$ [vol./vol.] $\mathrm{HCl}$ in $70 \%$ [vol./vol.] ethanol), followed by centrifugation $(20,000 \mathrm{~g}, 10 \mathrm{~min})$ and measurement of insulin content as above.

Statistical analysis Statistical analysis was performed by ANOVA or Student's $t$ test, as indicated. A value of $p<0.05$ was considered significant.

\section{Results}

To determine whether the mouse pancreas contains a circadian clock, as reported in rats $[8,9]$, we cultured pancreas explants from Bmall-Luc mice, a circadian reporter line [7]. The explants exhibited robust circadian rhythms of bioluminescence (Fig. 1a), demonstrating the presence of an autonomous clock. We detected co- 
a
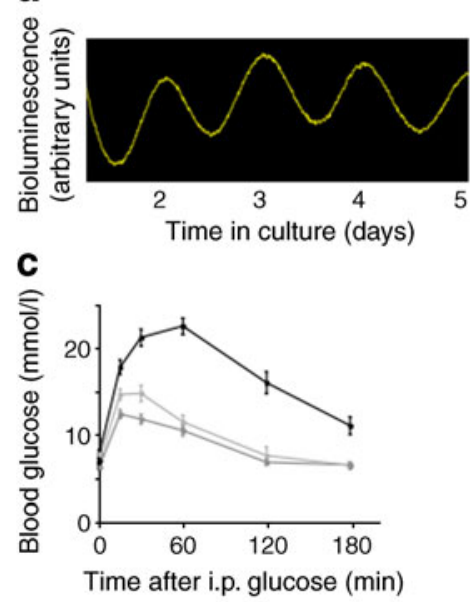

f
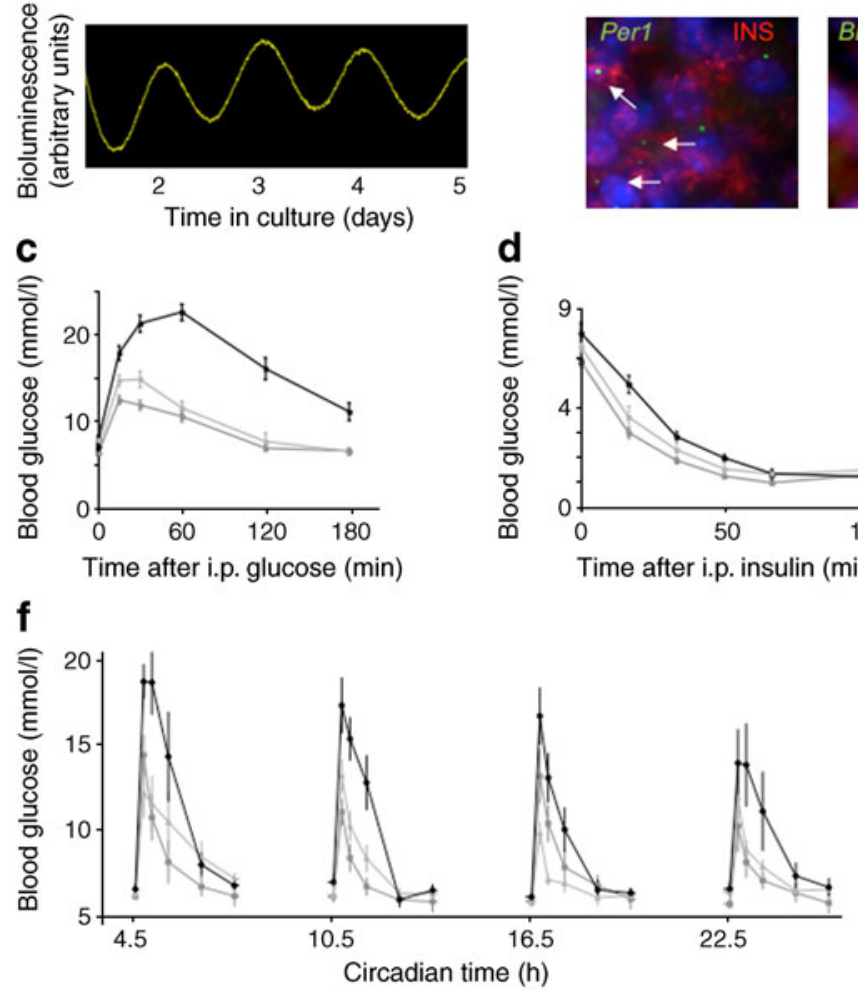

b
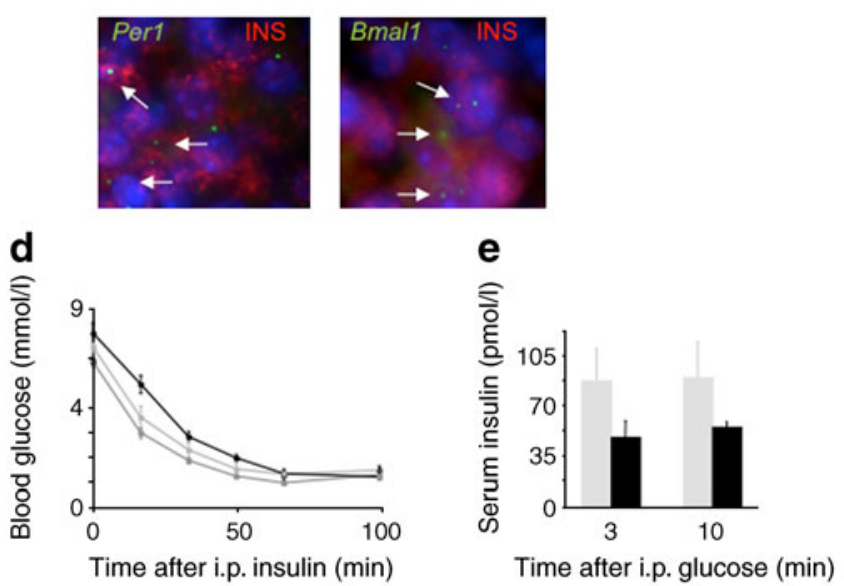

g

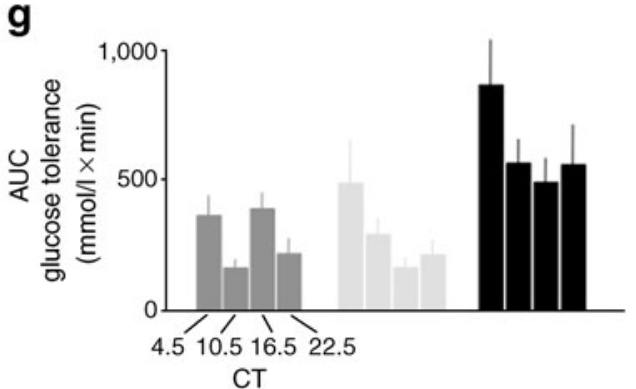

Fig. 1 Glucose intolerance and defective insulin secretion in mice selectively lacking an intrinsic circadian clock of the pancreas. a Presence of an autonomous circadian clock in the pancreas. Real-time bioluminescence output of an explanted pancreas from a Bmall-Luc circadian reporter mouse [7]. b Combined immunohistochemistry and fluorescence in situ hybridisation to pancreas sections showing copresence of insulin protein (red) and circadian clock component mRNA Perl and Bmall as labelled (both green) in pancreatic islets. Punctate appearance of fluorescence signal for mRNAs is typical. Hoechst stain (blue) shows positions of cell nuclei. Arrows, doublelabelled cells. c Glucose tolerance test performed at Zeitgeber time (ZT) $4.5 \mathrm{~h}$ in mice selectively lacking circadian clocks in the pancreas

expression of insulin and core clock component mRNAs (Fig. 1b), strongly suggesting that the insulin-producing beta cells of islets are among the pancreatic cell-types possessing an intrinsic clock.

We next tested the hypothesis that an intrinsic circadian clock of the pancreas is important for glucose homeostasis. To generate mice with selective genetic ablation of clock function in the pancreas (Panc-Bmall ${ }^{-/}$mice), we crossed Bmall conditional mice [6] with the Pdxl-Cre line [5]. As previously reported, $\mathrm{Pdxl}$-Cre showed recombination activity throughout the pancreas and scattered activity in the duodenum, but no detectable activity in other peripheral tissues (ESM Fig. 1a). We detected no Cre activity in the $\mathrm{SCN}$ or in most of the brain, but did detect activity in the arcuate nucleus, ventromedial hypothalamus and dorsomedial hypothalamus (ESM Fig. 1b). Because these hypothalamic structures are well known to contribute to
(Panc-Bmal1 ${ }^{-1}$; C57BL/6-129 hybrid) and littermate control genotypes. Mice used: Bmal1 ${ }^{l o x} / l o x$, Bmall conditional allele homozygote without $\mathrm{Cre}$; $\mathrm{Pdx}$-Cre, single copy of $\mathrm{Cre}$ transgene and wild-type Bmall. $p<0.001$ (ANOVA). d Insulin tolerance tests, as above (c). No significant difference between genotypes (ANOVA). e Serum insulin concentrations at the indicated times after glucose administration. $p<$ 0.02 (ANOVA). f Circadian profile of glucose tolerance for the three genotypes ( $n=9-10$ per genotype). g Quantification of circadian glucose tolerance curves shown above (f). CT, circadian time for all groups as for dark grey bars. c-g Values are mean \pm SEM. Light grey, Pdxl-Cre; dark grey, Bmall ${ }^{\text {lox/lox }}$; black, Panc-Bmal1 ${ }^{-/-}$

the neural regulation of glucose metabolism, this finding makes it essential to document a physiological defect in isolated pancreatic islets before concluding that a glucose homeostasis defect caused by $P d x 1-C r e$ recombination is of pancreatic origin. In Panc-Bmal1 ${ }^{-/}$mice, deletion of the conditional Bmall allele (ESM Fig. 2a) was consistent with the results of the indicator cross (ESM Fig. 1a). As expected, the protein brain, muscle Arnt-like 1 (BMAL1) was selectively lost from the pancreas (ESM Fig. 2b).

Unlike $\mathrm{Bmall}^{-/}$mice lacking BMAL1 in all tissues [2], Panc-Bmall ${ }^{-/}$mice exhibited normal locomotor activity, feeding behaviour, adiposity and body weight (ESM Fig. 3). Panc-Bmall ${ }^{-/}$mice had an abnormality of glucose homeostasis essentially identical to that of $\mathrm{Bmall}^{-/}$mice [2], characterised by severe glucose intolerance, normal responsiveness to insulin and defective insulin secretion in response to glucose (Fig. 1c-e). Panc-Bmal1 ${ }^{-/}$mice exhibited 


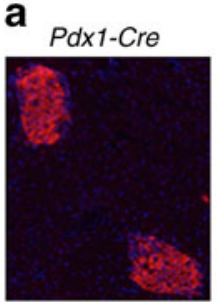

d

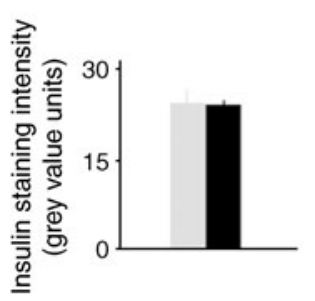

Panc-Bmal1 ${ }^{-1-}$

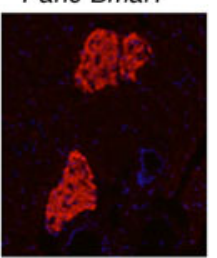

e

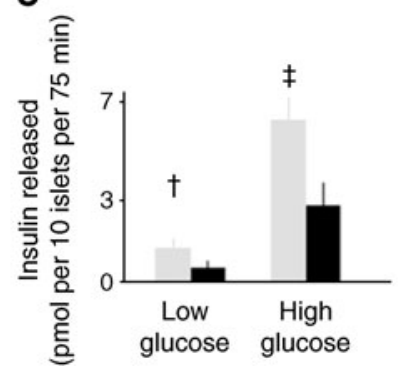

c
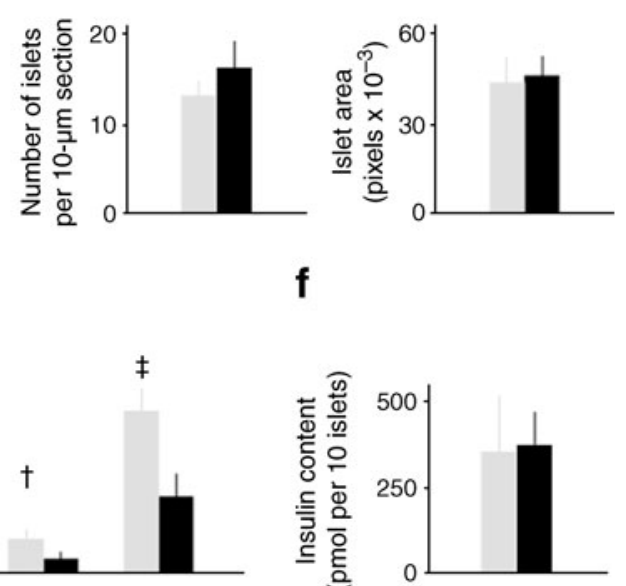

Fig. 2 Defective glucose-stimulated insulin secretion from pancreatic islets of mice selectively lacking an intrinsic circadian clock of the pancreas. a Normal general appearance of pancreatic islets in Panc$\mathrm{Bmal1}^{-1}$ mice vs $\mathrm{Pdx}$-Cre. Immunofluorescence micrographs of pancreas sections were stained for insulin. b-d No significant differences were detected between Panc-Bmall ${ }^{-/-}$mice and littermate controls in variables reflecting the number, size or insulin expression

intolerance to glucose throughout the circadian cycle, but a modest circadian modulation of glucose tolerance similar to that of controls persisted (Fig. 1f, g). Thus at least one clock outside the pancreas contributes to the circadian regulation of circulating glucose. The most likely candidate is the SCN clock, thought to modulate insulin secretion or sensitivity via autonomic efferents [1].

Pancreatic islets of Panc-Bmall ${ }^{-/-}$mice were indistinguishable in appearance from those of littermate Pdxl-Cre controls (Fig. 2a) and no significant difference was found between genotypes in the numbers of islets, mean size of islets or intensity of islet staining for insulin (Fig. 2b-d). Thus it is unlikely that the glucose intolerance and defective insulin secretion of Panc-Bmal1 ${ }^{-/}$mice reflects a gross abnormality of islet development. Isolated, cultured islets from Panc-Bmall ${ }^{-/}$mice secreted significantly less insulin in low and high glucose than islets from littermate $P d x 1$ Cre controls (Fig. 2e). There was no significant difference between genotypes in the total content of insulin per islet (Fig. 2f), indicating that the phenotype results from a defect in insulin secretion rather than insulin synthesis.

\section{Discussion}

Previous reports of clock gene expression in the pancreas [8] and rhythmic insulin release from isolated islets [9] suggested that a pancreatic clock regulates glucose homeostasis in vivo, a hypothesis our experiments have explicitly of pancreatic islets (Student's $t$ test). e Defective insulin secretion from isolated islets of Panc-Bmall ${ }^{-/}$mice under low and high glucose conditions, ${ }^{\dagger} p=0.03,{ }^{\ddagger} p=0.002$ (Student's $t$ test). f No significant difference in total insulin content of isolated islets from Panc-Bmal1 ${ }^{-/}$ mice and control littermates (Student's $t$ test). b-f Values are mean \pm SEM. Light grey, Pdx1-Cre; black, Panc-Bmal1

tested. Our results indicate that the Bmall gene, and probably circadian clock function, is required in the pancreas for normal insulin secretion and normal glucose homeostasis. The glucose intolerance of Panc-Bmal1 ${ }^{-/}$ mice is essentially identical to that of $\mathrm{Bmall}^{-/}$mice [2], indicating that the loss of SCN clock function and consequent behavioural abnormalities in $\mathrm{Bmall}^{-/}$mice contribute little, if anything to the glucose homeostasis phenotype. A similar, independent analysis has recently been reported [10].

We do not know the molecular mechanism underlying the defect in insulin release in Panc-Bmall ${ }^{-1}$ mice. The known role of clocks in regulating cell-autonomous gene expression suggests that a circadian clock within pancreatic beta cells regulates levels of one or more proteins of the glucose-sensing and/or insulin secretion pathways. In the absence of BMAL1, levels of one or more such proteins might fall below the usual circadian trough value, limiting insulin secretion. Our results provide evidence for a previously-unrecognised molecular regulator of pancreatic glucose-sensing and/or insulin secretion.

Acknowledgements We thank D. Melton (Harvard University, Cambridge, MA, USA) for Pdxl-Cre mice, B. Lowell and D. Kong (Beth Israel Deaconess Medical Center, Boston, MA, USA) for advice and M. Liu (Department of Neurobiology, Harvard Medical School, Boston, MA, USA) for technical assistance. This work was supported by NIH grant R01 NS060860 (to C. J. Weitz), a Merck Fellowship of the Life Sciences Research Foundation (to K. A. Lamia), a Training Program in Sleep, Circadian and Respiratory Neurobiology Pre-Doctoral 
Fellowship T32 HL07901 (to L. A. Sadacca), and a Research Training in Digestive Diseases Fellowship T32 DK07191 (to A. S. deLemos). B. Blum is supported by an EMBO long-term postdoctoral fellowship.

Duality of interest The authors declare that there is no duality of interest associated with this manuscript.

Open Access This article is distributed under the terms of the Creative Commons Attribution Noncommercial License which permits any noncommercial use, distribution, and reproduction in any medium, provided the original author(s) and source are credited.

\section{References}

1. La Fleur SE, Kalsbeek A, Wortel J, Fekkes ML, Buijs RM (2001) A daily rhythm in glucose tolerance: a role for the suprachiasmatic nucleus. Diabetes 50:1237-1243

2. Lamia KA, Storch K-F, Weitz CJ (2008) Physiological significance of a peripheral tissue circadian clock. Proc Natl Acad Sci U S A 105:15172-15177
3. Turek FW, Joshu C, Kohsaka A et al (2005) Obesity and metabolic syndrome in circadian Clock mutant mice. Science 308:1043-1045

4. Rudic RD, McNamara P, Curtis AM et al (2004) BMAL1 and CLOCK, two essential components of the circadian clock, are involved in glucose homeostasis. PLoS Biol 2:e377

5. Gu G, Dubauskaite J, Melton DA (2002) Direct evidence for the pancreatic lineage: NGN3+ cells are islet progenitors and are distinct from duct progenitors. Development 129:2447-2457

6. Storch K-F, Paz C, Signorovitch J et al (2007) Intrinsic circadian clock of the mammalian retina: importance for retinal processing of visual information. Cell 130:730-741

7. Robles MS, Boyault C, Knutti D, Padmanabhan K, Weitz CJ (2010) Identification of RACK1 and protein kinase C alpha as integral components of the mammalian circadian clock. Science 327:463-466

8. Mühlbauer E, Wolgast S, Finckh U, Peschke D, Peschke E (2004) Indication of circadian oscillations in the rat pancreas. FEBS Lett 564:91-96

9. Peschke E, Peschke D (1998) Evidence for a circadian rhythm of insulin release from perifused rat pancreatic islets. Diabetologia 41:1085-1092

10. Marcheva B, Ramsey KM, Buhr ED et al (2010) Disruption of the clock components CLOCK and BMAL1 leads to hypoinsulinaemia and diabetes. Nature 466:627-631 